\title{
Hancock must act, as year-long wait for tooth extractions set to lengthen
}

The British Dental Association has joined with sector leaders and learning disability charity Mencap to press Matt Hancock to set out an action plan to ease the backlog on tooth extractions in hospitals, warning many young and vulnerable patients across England are now expected to see waiting times of up to a year lengthen significantly.

Extractions, performed under general anaesthetic on children and adults some with a complex mix of medical conditions, including autism and learning difficulties, are the responsibility of community dental services and hospital dental services. Frontline intelligence gathered by the BDA across the English regions suggest many services have yet to resume treatment since the start of lockdown, and where they have, the capacity has often halved to meet social distancing and additional infection control procedures.

Tooth decay has been immovable as the number one reason for hospital admissions among young children, with recent analysis by the Local Government Association indicating 180 procedures took place every working day in England in 2018/19 on patients aged under 18.

Extractions formed part of the many elective procedures that were postponed among 50,000 children from March to May. High demand and underinvestment had seen waiting times hit over a year prior to the pandemic, a figure which is now expected to surge. Official targets for delivering treatment vary by area from 4 to 18 weeks, owing to different approaches to commissioning services.

In an open letter to the Health Secretary the group has called for an urgent action plan, and to publish an internal Public Health England review into the true scale of extractions under general anaesthetic, which is thought to be significantly understated in official statistics.

Charlotte Waite, Chair of the BDA's

England Community Dental Services

Committee said: 'The hundreds of

extractions that took place every day in our hospitals ended with the start of lockdown,

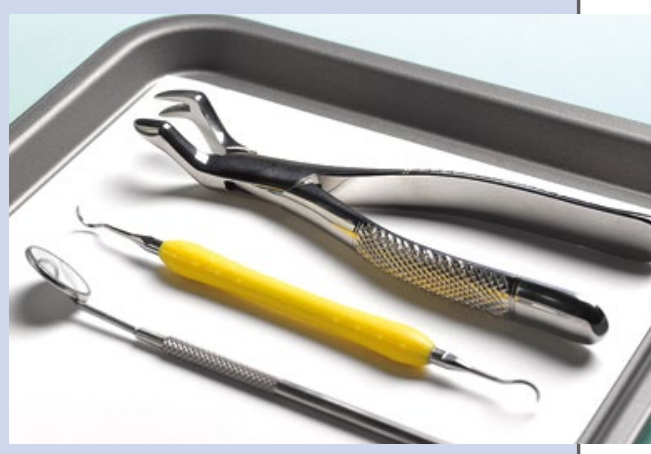

but demand hasn't gone anywhere.

'Increasingly stretched services are now struggling to meet the backlog, while tens of thousands of vulnerable adults and young children wait in pain.

'The government has a responsibility to act for patients, many of whom who were already facing a year of toothache and the impact this has on their general wellbeing.

'We need a plan, and full disclosure on the true scale of a problem that is already a national scandal.'

\section{College of General Dentistry appoints new Ambassadors}

The College of General Dentistry is delighted to announce the further development of its 'College Ambassadors' scheme with the appointment of two new Ambassadors, Professor Jason Leitch CBE and Professor Jacky Hayden CBE.

College Ambassadors are drawn from different backgrounds and walks of life. They support engagement of the College in society, and promote its influence in the interests of patients, building trust and confidence in the College and dental healthcare professionals. Ambassadors help the College ensure dentistry is properly recognised for its importance as an integral element of general healthcare and wellbeing. Ambassadors support the College's mission to promote preventatively orientated, minimum interventive, patient-centred, longitudinal care.

More Ambassadors will be appointed in the coming months as the College works towards its historic, formal launch, rescheduled for early 2021, COVID restrictions permitting.

Chair of the College Board of Trustees, Professor Nairn Wilson, said: 'The Board of Trustees of the College is delighted to further develop the College Ambassador scheme with the appointment of Professors Jason Leitch and Jacky Hayden, both of whom have a wealth of experience and expertise. The College greatly looks forward to working with its new

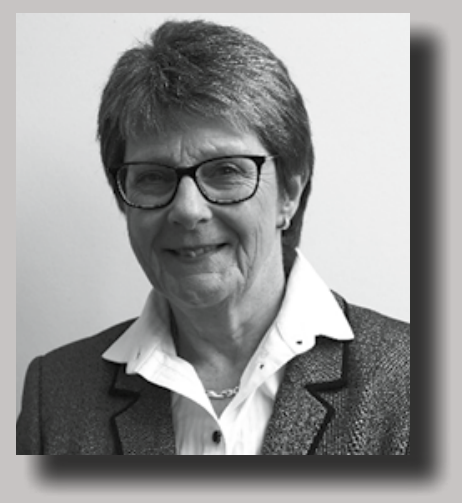
(a)

Ambassadors in realising its immediate and longer-term goals, including reaching out to all stakeholders, including patients and other healthcare professions, to enhance the effectiveness, standing and status of dentistry.'

Commenting on his appointment Jason Leitch said: 'It is a huge honour to be invited to be an Ambassador for the College of General Dentistry. As National Clinical Director of the Scottish Government, the advancement of quality in all areas of healthcare is close to my heart. It is an exciting time for dentistry, and I am delighted to contribute to the initiative to form the College.'

Jacky Hayden said: 'I am honoured to accept the invitation to be an ambassador for the College of General Dentistry. General Dentistry has led the way in postgraduate dental education, and it is a tribute to all involved that the aspiration for an independent College is now being realised. Our health care system needs generalists and the special skills that they bring in promoting good health and preventing disease. Congratulations to all involved.' 